\title{
Nota prévia sobre uma Guttiferae nova da Amazônia
}

\author{
Maria Elisabeth van den Berg ( $\left.{ }^{*}\right)$
}

\begin{abstract}
Resumo
Descrição sumária de uma nova espécie de Rheedia, endêmica na região do Rio Negro (Amazônia Ocidental).
\end{abstract}

Em estudo feito sobre o gênero Rheedia L. (Guttiferae), entre o material pertencente aos herbários do Museu Goeldi (MG), Instituto Nacional de Pesquisas da Amazônia (INPA) e Empresa Brasileira de Pesquisas Agropecuárias (IAN), encontramos vários exemplares, semelhantes entre si, mas totalmente diferentes das demais espécies conhecidas na América do Sul. Após pesquisas adicionais, chegamos à conclusão de que se trata de uma espécie nova para a Ciência.

Como todas as coleções apresentam somente frutos, achamos oportuno aguardar uma coleção com flores, muito embora na diferenciação das Rheedia seja fundamental a morfologia pomológica.

Esta nova espécie de Rheedia, que é endêmica na região do rio Negro, tem ramos, folhas e frutos muito típicos e díspares das outras espécies amazônicas.

De acordo com o tipo de epicarpo que o seu fruto apresenta -- liso - a espécie em questão deve ser enquadrada na secção EURHEEDIA Planchon et Triana.

São apontadas apenas as principais características desta espécie, para oportunamente ser publicada a diagnose completa de:

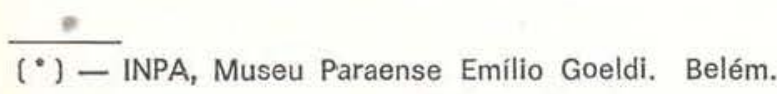

Rheedia albuquerquei van den Berg $n . s p$.

Arbor circa $7 \mathrm{~m}$ alta, diametro circa $10 \mathrm{~cm}$; ramuli apicem versus angulosi; folia oblongoelliptica vel ovata, coriacea, glabra et opaca, apice obtuso. Fructus: baccae elipsoideae assymetricae, circa $2 \mathrm{~cm}$ longae, diametro $1,5 \mathrm{~cm}$, glabrae, nitidissimae

Species claro collega Pe. José Maria Albuquerque dedicata.

HOLOTYPUS: BRASIL: Estado do Amazonas: Rio Negro, Ilha Gavião, "near mouth of Rio Branco"; 5-VII/ 12-VIII-1967; R. E. Schultes 24535 (INPA).

\section{AGRADECIMIENTO}

Ao botânico João Murça Pires pela revisão ća diagnose latina.

\section{SUMMARY}

In this note, one new species of Guttiferae Rheedia albuquerquei is proposed. It is placed in the section EURHEEDIA Planchon et Triana. This species is distinct from all other Rheedia by the remarkable angulate and cinereous branchlets, coriaceous blades and glabrous assimetric elipsoid fruits. 